\title{
On best proximity point of $\psi$-Geraghty contractions
}

\section{Erdal Karapınar}

\section{"Correspondence:}

erdalkarapinar@yahoo.com

Department of Mathematics, Atilim University, Incek, Ankara 06836, Turkey

\begin{abstract}
Very recently, Caballero, Harjani and Sadarangani (Fixed Point Theory Appl. 2012:231, 2012) observed some best proximity point results for Geraghty contractions by using the $P$-property. In this paper, we introduce the notion of $\psi$-Geraghty contractions and show the existence and uniqueness of the best proximity point of such contractions in the setting of a metric space. We state examples to illustrate our result. MSC: $41 \mathrm{~A} 65 ; 90 \mathrm{C} 30 ; 47 \mathrm{H} 10$
\end{abstract}

Keywords: best proximity point; non-self mapping; partial order; metric space; fixed point

\section{Introduction and preliminaries}

In nonlinear functional analysis, fixed point theory and best proximity point theory play a crucial role in the establishment of the existence of certain differential and integral equations. As a consequence, fixed point theory is very useful for various quantitative sciences that involve such equations. To list a few, certain branches of computer sciences, engineering and economics are well-known examples in which fixed point theory is used.

The most remarkable paper in this field was reported by Banach [1] in 1922. In this paper, Banach proved that every contraction in a complete metric space has a unique fixed point. Following this outstanding paper, many authors have extended, generalized and improved this remarkable fixed point theorem of Banach by changing either the conditions of the mappings or the construction of the space. In particular, one of the notable generalizations of Banach fixed point theorem was reported by Geraghty [2].

Theorem 1.1 (Geraghty [2]) Let $(X, d)$ be a complete metric space and $T: X \rightarrow X$ be an operator. Suppose that there exists $\beta:(0, \infty) \rightarrow[0,1)$ satisfying the condition

$$
\beta\left(t_{n}\right) \rightarrow 1 \text { implies } t_{n} \rightarrow 0 .
$$

If $T$ satisfies the following inequality:

$$
d(T x, T y) \leq \beta(d(x, y)) d(x, y) \quad \text { for any } x, y \in X,
$$

then $T$ has a unique fixed point.

(0) 2013 Karapınar; licensee Springer. This is an Open Access article distributed under the terms of the Creative Commons Attribution License (http://creativecommons.org/licenses/by/2.0), which permits unrestricted use, distribution, and reproduction in any medium, provided the original work is properly cited. 
It is very natural that some mappings, especially non-self-mappings defined on a complete metric space $(X, d)$, do not necessarily possess a fixed point, that is, $d(x, T x)>0$ for all $x \in X$. In such situations, it is reasonable to search for the existence (and uniqueness) of a point $x^{*} \in X$ such that $d\left(x^{*}, T x^{*}\right)$ is an approximation of an $x \in X$ such that $d(x, T x)=0$. In other words, one speculates to determine an approximate solution $x^{*}$ that is optimal in the sense that the distance between $x^{*}$ and $T x^{*}$ is minimum. Here, the point $x^{*} \in X$ is called a best proximity point.

This research subject has attracted attention of a number of authors; for example, see [2-23]. In this paper we generalize and improve certain results of Caballero et al. in [6]. Notice also that in the best proximity point theory, we usually consider a non-selfmapping. In fixed point theory, almost all maps are self-mappings. For the sake of completeness, we recall some basic definitions and fundamental results on the best proximity theory.

Let $(X, d)$ be a metric space and $A$ and $B$ be nonempty subsets of a metric space $(X, d)$. A mapping $T: A \rightarrow B$ is called a $k$-contraction if there exists $k \in(0,1)$ such that $d(T x, T y) \leq$ $k d(x, y)$ for any $x, y \in A$. It is clear that a $k$-contraction coincides with the celebrated Banach fixed point theorem if one takes $A=B$, where $A$ is a complete subset of $X$.

Let $A$ and $B$ be two nonempty subsets of a metric space $(X, d)$. We denote by $A_{0}$ and $B_{0}$ the following sets:

$$
\begin{aligned}
& A_{0}=\{x \in A: d(x, y)=d(A, B) \text { for some } y \in B\}, \\
& B_{0}=\{y \in B: d(x, y)=d(A, B) \text { for some } x \in A\},
\end{aligned}
$$

where $d(A, B)=\inf \{d(x, y): x \in A, y \in B\}$.

In [13], the authors presented sufficient conditions which determine when the sets $A_{0}$ and $B_{0}$ are nonempty. In [19], the author introduced the following definition.

Definition 1.1 Let $(A, B)$ be a pair of nonempty subsets of a metric space $(X, d)$ with $A_{0} \neq \emptyset$. Then the pair $(A, B)$ is said to have the $P$-property if and only if for any $x_{1}, x_{2} \in A_{0}$ and $y_{1}, y_{2} \in B_{0}$,

$$
d\left(x_{1}, y_{1}\right)=d(A, B) \quad \text { and } \quad d\left(x_{2}, y_{2}\right)=d(A, B) \quad \Rightarrow \quad d\left(x_{1}, x_{2}\right)=d\left(y_{1}, y_{2}\right)
$$

It can be easily seen that for any nonempty subset $A$ of $(X, d)$, the pair $(A, A)$ has the $P$-property. In [19], the author proved that any pair $(A, B)$ of nonempty closed convex subsets of a real Hilbert space $H$ satisfies the $P$-property. Now, we introduce the class $F$ of those functions $\beta:(0, \infty) \rightarrow[0,1)$ satisfying the following condition:

$$
\beta\left(t_{n}\right) \rightarrow 1 \text { implies } t_{n} \rightarrow 0 \text {. }
$$

Definition 1.2 (See [6]) Let $A, B$ be two nonempty subsets of a metric space $(X, d)$. A mapping $T: A \rightarrow B$ is said to be a Geraghty-contraction if there exists $\beta \in F$ such that

$$
d(T x, T y) \leq \beta(d(x, y)) \cdot d(x, y) \quad \text { for any } x, y \in A
$$

Theorem 1.2 (See [6]) Let $(A, B)$ be a pair of nonempty closed subsets of a complete metric space $(X, d)$ such that $A_{0}$ is nonempty. Let $T: A \rightarrow B$ be a continuous Geraghty-contraction 
satisfying $T\left(A_{0}\right) \subseteq B_{0}$. Suppose that the pair $(A, B)$ has the P-property. Then there exists a unique $x^{*}$ in $A$ such that $d\left(x^{*}, T x^{*}\right)=d(A, B)$.

In the following section, we improve the theorem above by using a distance function $\psi$ in Definition 1.2. In particular, we introduce Definition 2.1 and broaden the scope of Theorem 1.2 to $\psi$-Geraghty-contractions.

\section{Main results}

We start this section with the definition of the following auxiliary function. Let $\Psi$ denote the class of functions $\psi:[0, \infty) \rightarrow[0, \infty)$ which satisfy the following conditions:

(a) $\psi$ is nondecreasing;

(b) $\psi$ is subadditive, that is, $\psi(s+t) \leq \psi(s)+\psi(t)$;

(c) $\psi$ is continuous;

(d) $\psi(t)=0 \Leftrightarrow t=0$.

We introduce the following contraction.

Definition 2.1 Let $A, B$ be two nonempty subsets of a metric space $(X, d)$. A mapping $T: A \rightarrow B$ is said to be a $\psi$-Geraghty contraction if there exists $\beta \in F$ such that

$$
\psi(d(T x, T y)) \leq \beta(\psi(d(x, y))) \psi(d(x, y)) \quad \text { for any } x, y \in A \text {. }
$$

Remark 2.1 Notice that since $\beta:(0, \infty) \rightarrow[0,1)$, we have

$$
\psi(d(T x, T y)) \leq \beta(\psi(d(x, y))) \psi(d(x, y))<\psi(d(x, y)) \quad \text { for any } x, y \in A \text { with } x \neq y \text {. }
$$

We are now ready to state and prove our main theorem.

Theorem 2.1 Let $(A, B)$ be a pair of nonempty closed subsets of a complete metric space $(X, d)$ such that $A_{0}$ is nonempty. Let $T: A \rightarrow B$ be a $\psi$-Geraghty contraction satisfying $T\left(A_{0}\right) \subseteq B_{0}$. Suppose that the pair $(A, B)$ has the P-property. Then there exists a unique $x^{*}$ in $A$ such that $d\left(x^{*}, T x^{*}\right)=d(A, B)$.

Proof Regarding that $A_{0}$ is nonempty, we take $x_{0} \in A_{0}$. Since $T x_{0} \in T\left(A_{0}\right) \subseteq B_{0}$, we can find $x_{1} \in A_{0}$ such that $d\left(x_{1}, T x_{0}\right)=d(A, B)$. Analogously, regarding the assumption $T x_{1} \in$ $T\left(A_{0}\right) \subseteq B_{0}$, we determine $x_{2} \in A_{0}$ such that $d\left(x_{2}, T x_{1}\right)=d(A, B)$. Recursively, we obtain a sequence $\left\{x_{n}\right\}$ in $A_{0}$ satisfying

$$
d\left(x_{n+1}, T x_{n}\right)=d(A, B) \quad \text { for any } n \in \mathbb{N} .
$$

Since $(A, B)$ has the $P$-property, we derive that

$$
d\left(x_{n}, x_{n+1}\right)=d\left(T x_{n-1}, T x_{n}\right) \quad \text { for any } n \in \mathbb{N} .
$$

If there exists $n_{0} \in \mathbb{N}$ such that $d\left(x_{n_{0}}, x_{n_{0}+1}\right)=0$, then the proof is completed. Indeed,

$$
0=d\left(x_{n_{0}}, x_{n_{0}+1}\right)=d\left(T x_{n_{0}-1}, T x_{n_{0}}\right),
$$


and consequently, $T x_{n_{0}-1}=T x_{n_{0}}$. On the other hand, due to (8) we have

$$
d\left(x_{n_{0}}, T x_{n_{0}-1}\right)=d(A, B) .
$$

Therefore, we conclude that

$$
d(A, B)=d\left(x_{n_{0}}, T x_{n_{0}-1}\right)=d\left(x_{n_{0}}, T x_{n_{0}}\right) .
$$

For the rest of the proof, we suppose that $d\left(x_{n}, x_{n+1}\right)>0$ for any $n \in \mathbb{N}$. Since $T$ is a $\psi$-Geraghty contraction, for any $\mathbb{N}$, we have that

$$
\begin{aligned}
\psi\left(d\left(x_{n}, x_{n+1}\right)\right) & =\psi\left(d\left(T x_{n-1}, T x_{n}\right)\right) \\
& \leq \beta\left(\psi\left(d\left(x_{n-1}, x_{n}\right)\right)\right) \psi\left(d\left(x_{n-1}, x_{n}\right)\right) \\
& <\psi\left(d\left(x_{n-1}, x_{n}\right)\right) .
\end{aligned}
$$

Consequently, $\left\{\psi\left(d\left(x_{n}, x_{n+1}\right)\right)\right\}$ is a nonincreasing sequence and bounded below, and so $\lim _{n \rightarrow \infty} \psi\left(d\left(x_{n}, x_{n+1}\right)\right)=L$ exists. Let $\lim _{n \rightarrow \infty} \psi\left(d\left(x_{n}, x_{n+1}\right)\right)=L \geq 0$. Assume that $L>0$. Then, from (6), we have

$$
\frac{\psi\left(d\left(x_{n+1}, x_{n+2}\right)\right)}{\psi\left(d\left(x_{n}, x_{n+1}\right)\right)} \leq \beta\left(\psi\left(d\left(x_{n}, x_{n+1}\right)\right)\right) \leq 1
$$

for each $n \geq 1$, which implies that

$$
\lim _{n \rightarrow \infty} \beta\left(\psi\left(d\left(x_{n}, x_{n+1}\right)\right)\right)=1 .
$$

On the other hand, since $\beta \in F$, we conclude $L=0$, that is,

$$
\lim _{n \rightarrow \infty} \psi\left(d\left(x_{n}, x_{n+1}\right)\right)=0 \text {. }
$$

Notice that since $d\left(x_{n+1}, T x_{n}\right)=d(A, B)$ for any $n \in \mathbb{N}$, for fixed $p, q \in \mathbb{N}$, we have $d\left(x_{p}, T x_{p-1}\right)=d\left(x_{q}, T x_{q-1}\right)=d(A, B)$, and since $(A, B)$ satisfies the $P$-property, $d\left(x_{p}, x_{q}\right)=$ $d\left(T x_{p-1}, T x_{q-1}\right)$. In what follows, we prove that $\left\{x_{n}\right\}$ is a Cauchy sequence. On the contrary, assume that we have

$$
\varepsilon=\limsup _{m, n \rightarrow \infty} d\left(x_{n}, x_{m}\right)>0 .
$$

By using the triangular inequality,

$$
d\left(x_{n}, x_{m}\right) \leq d\left(x_{n}, x_{n+1}\right)+d\left(x_{n+1}, x_{m+1}\right)+d\left(x_{m+1}, x_{m}\right) .
$$

By (12) and since $d\left(x_{n+1}, x_{m+1}\right)=d\left(T x_{n}, T x_{m}\right)$, by the comment mentioned above, regarding the discussion on the $P$-property above together with (12), (15) and the property of the 
function $\psi$, we derive that

$$
\begin{aligned}
\psi\left(d\left(x_{n}, x_{m}\right)\right) & \leq \psi\left(d\left(x_{n}, x_{n+1}\right)+d\left(T x_{n}, T x_{m}\right)+d\left(x_{m+1}, x_{m}\right)\right) \\
& \leq \psi\left(d\left(x_{n}, x_{n+1}\right)\right)+\psi\left(d\left(T x_{n}, T x_{m}\right)\right)+\psi\left(d\left(x_{m+1}, x_{m}\right)\right) \\
& \leq \psi\left(d\left(x_{n}, x_{n+1}\right)\right)+\beta\left(\psi\left(d\left(x_{n}, x_{m}\right)\right)\right) \psi\left(d\left(x_{n}, x_{m}\right)\right)+\psi\left(d\left(x_{m+1}, x_{m}\right)\right) .
\end{aligned}
$$

By a simple manipulation, (16) yields that

$$
\psi\left(d\left(x_{n}, x_{m}\right)\right) \leq\left(1-\beta\left(\psi\left(d\left(x_{n}, x_{m}\right)\right)\right)\right)^{-1}\left[\psi\left(d\left(x_{n}, x_{n+1}\right)\right)+\psi\left(d\left(x_{m+1}, x_{m}\right)\right)\right] .
$$

By taking the properties of the function $\psi$ into account, together with (13) and $\limsup _{m, n \rightarrow \infty} d\left(x_{n}, x_{m}\right)=\varepsilon>0$ and $\lim _{n \rightarrow \infty} d\left(x_{n}, x_{n+1}\right)=0$, the last inequality yields

$$
\limsup _{m, n \rightarrow \infty}\left(1-\beta\left(\psi\left(d\left(x_{n}, x_{m}\right)\right)\right)\right)^{-1}=\infty
$$

Therefore $\lim \sup _{m, n \rightarrow \infty} \beta\left(\psi\left(d\left(x_{n}, x_{m}\right)\right)\right)=1$. By taking the fact $\beta \in F$ into account, we get

$$
\limsup _{m, n \rightarrow \infty} \psi\left(d\left(x_{n}, x_{m}\right)\right)=0
$$

Regarding the properties of the function $\psi$, the limit above contradicts the assumption (14). Therefore, $\left\{x_{n}\right\}$ is a Cauchy sequence.

Since $\left(x_{n}\right) \subset A$ and $A$ is a closed subset of the complete metric space $(X, d)$, we can find $x^{*} \in A$ such that $x_{n} \rightarrow x^{*}$.

We claim that $T x_{n} \rightarrow T x^{*}$. Suppose, on the contrary, that $T x_{n} \nrightarrow T x^{*}$. This means that we can find $\varepsilon>0$ such that for each $n \in \mathbb{N}$, there exists $p_{n}$ with

$$
\varepsilon<d\left(T x_{p_{n}}, T x^{*}\right)
$$

Due to the properties of $\psi$, we get

$$
0<\psi(\varepsilon) \leq \psi\left(d\left(T x_{p_{n}}, T x^{*}\right)\right) .
$$

Using the fact that $T$ is a $\psi$-Geraghty contraction, we have

$$
\psi(\varepsilon) \leq \psi\left(d\left(T x_{p_{n}}, T x^{*}\right)\right) \leq \beta\left(\psi\left(d\left(x_{p_{n}}, x^{*}\right)\right)\right) \psi\left(d\left(x_{p_{n}}, x^{*}\right)\right)
$$

for any $n \in \mathbb{N}$. Since $x_{p_{n}} \rightarrow x^{*}$ and $\psi\left(d\left(x_{p_{n}}, x_{p_{n+1}}\right)\right) \rightarrow 0$, we can find $n_{0}$ such that for $n \geq n_{0}$

$$
\psi\left(d\left(x_{p_{n}}, x^{*}\right)\right)<\psi(\varepsilon) \text { and } \psi\left(d\left(x_{p_{n}}, x_{p_{n+1}}\right)\right)<\psi(\varepsilon)
$$

Consequently, for $n \geq n_{0}$ we have

$$
\begin{aligned}
0 & <\psi(\varepsilon) \leq \psi\left(d\left(T x_{p_{n}}, T x^{*}\right)\right) \leq \beta\left(\psi\left(d\left(x_{p_{n}}, x^{*}\right)\right)\right) \psi\left(d\left(x_{p_{n}}, x^{*}\right)\right) \\
& \leq \psi\left(d\left(x_{p_{n}}, x^{*}\right)\right)<\psi(\varepsilon)
\end{aligned}
$$

a contradiction. Therefore, $T x_{n} \rightarrow T x^{*}$. 
Regarding the fact that the sequence $\left\{d\left(x_{n+1}, T x_{n}\right)\right\}$ is a constant sequence with value $d(A, B)$, we derive

$$
d\left(x^{*}, T x^{*}\right)=d(A, B)
$$

which is equivalent to saying that $x^{*}$ is the best proximity point of $T$. This completes the proof of the existence of a best proximity point.

We shall show the uniqueness of the best proximity point of $T$. Suppose that $x^{*}$ and $y^{*}$ are two distinct best proximity points of $T$, that is, $x^{*} \neq y^{*}$. This implies that

$$
d\left(x^{*}, T x^{*}\right)=d(A, B)=d\left(y^{*}, T y^{*}\right) .
$$

Using the $P$-property, we have

$$
d\left(x^{*}, x_{2}\right)=d\left(T x^{*}, T y^{*}\right) .
$$

Using the fact that $T$ is a $\psi$-Geraghty contraction, we have

$$
\psi\left(d\left(x^{*}, y^{*}\right)\right)=\psi\left(d\left(T x^{*}, T y^{*}\right)\right) \leq \beta\left(\psi\left(d\left(x^{*}, y^{*}\right)\right)\right) \psi\left(d\left(x^{*}, y^{*}\right)\right)<\psi\left(d\left(x^{*}, y^{*}\right)\right),
$$

a contradiction. This completes the proof.

Notice that the pair $(A, A)$ satisfies the $P$-property for any nonempty subset $A$ of $X$. Consequently, we have the following corollary.

Corollary 2.1 Let $(X, d)$ be a complete metric space and $A$ be a nonempty closed subset of $X$. Let $T: A \rightarrow A$ be a $\psi$-Geraghty-contraction. Then $T$ has a unique fixed point.

Proof Apply Theorem 2.1 with $A=B$.

If we take $\psi(t)=t$ we obtain Theorem 1.2 as a corollary of Theorem 2.1.

Corollary 2.2 Let $(X, d)$ be a complete metric space and A be a nonempty closed subset of X. Let $T: A \rightarrow A$ be a Geraghty-contraction. Then $T$ has a unique fixed point.

Proof Apply Theorem 2.1 with $A=B$ and $\psi(t)=t$.

In order to illustrate our results, we present the following example.

Example 2.1 Suppose that $X=\mathbb{R}^{2}$ with the metric

$$
d\left((x, y),\left(x^{\prime}, y^{\prime}\right)\right)=\max \left\{\left|x-x^{\prime}\right|,\left|y-y^{\prime}\right|\right\}
$$

and consider the closed subsets

$$
\begin{aligned}
& A=\{(0, x): 0 \leq x<\infty\}, \\
& B=\{(1, x): 0 \leq x<\infty\}
\end{aligned}
$$

and $\psi(t)=\frac{t}{2}$ and $\beta(t)=\frac{\ln (1+t)}{t}$. 
Set $T: A \rightarrow B$ to be the mapping defined by

$$
T((0, x))=(1, \ln (1+x))
$$

Since $d(A, B)=1$, the pair $(A, B)$ has the $P$-property.

Notice that $A_{0}=A$ and $B_{0}=B$ and $T\left(A_{0}\right) \subseteq B_{0}$.

Without loss of generality, we assume that $x>x^{\prime}$. Moreover,

$$
d\left(T(0, x), T\left(0, x^{\prime}\right)\right)=\left|\ln (1+x)-\ln \left(1+x^{\prime}\right)\right|=\left|\ln \left(\frac{1+x}{1+x^{\prime}}\right)\right|
$$

and

$$
d\left((0, x),\left(0, x^{\prime}\right)\right)=\left|x-x^{\prime}\right|
$$

We have

$$
\begin{aligned}
\psi\left(d\left(T(0, x), T\left(0, x^{\prime}\right)\right)\right) & =\frac{1}{2}\left|\ln \left(\frac{1+x}{1+x^{\prime}}\right)\right|=\frac{1}{2}\left|\ln \left(\frac{1+x^{\prime}+x-x^{\prime}}{1+x^{\prime}}\right)\right| \\
& =\frac{1}{2}\left|\ln \left(1+\frac{x-x^{\prime}}{1+x^{\prime}}\right)\right| \\
& \leq \frac{1}{2} \ln \left(1+\left|x-x^{\prime}\right|\right) \quad(\text { since } \ln (1+t) \text { is strictly increasing }) \\
& \leq \ln \left(1+\frac{1}{2}\left|x-x^{\prime}\right|\right) \\
& \leq \frac{\ln \left(1+\frac{1}{2}\left|x-x^{\prime}\right|\right)}{\frac{1}{2}\left|x-x^{\prime}\right|} \frac{1}{2}\left|x-x^{\prime}\right| \\
& =\beta\left(\psi\left(d\left((0, x),\left(0, x^{\prime}\right)\right)\right)\right) \psi\left(d\left((0, x),\left(0, x^{\prime}\right)\right)\right)
\end{aligned}
$$

where $\beta:[0, \infty) \rightarrow[0,1)$ is defined as $\beta(t)=\frac{\ln (1+t)}{t}$.

Therefore, $T$ is a $\psi$-Geraghty-contraction. Notice that the pair $(A, B)$ satisfies the $P$-property. Indeed, if

$$
\begin{aligned}
& d\left((0, x),\left(1, x^{\prime}\right)\right)=\max \left\{1,\left|x-x^{\prime}\right|\right\}=d(A, B)=1, \\
& d\left((0, y),\left(1, y^{\prime}\right)\right)=\max \left\{1,\left|y-y^{\prime}\right|\right\}=d(A, B)=1
\end{aligned}
$$

then $x=x^{\prime}$ and $y=y^{\prime}$ and hence

$$
|x-y|=d((0, x),(0, y))=d\left(\left(1, x^{\prime}\right),\left(1, y^{\prime}\right)\right)=\left|x^{\prime}-y^{\prime}\right| .
$$

Therefore, since the assumptions of Theorem 2.1 are satisfied, by Theorem 2.1 there exists a unique $\left(0, x^{*}\right) \in A$ such that

$$
d\left(\left(0, x^{*}\right), T\left(0, x^{*}\right)\right)=1=d(A, B) .
$$

More precisely, the point $(0,0) \in A$ is the best proximity point of $T$. 
Example 2.2 Let $X=\mathbb{R}$ and $d(x, y)=|x-y|$ be a metric on $X$. Suppose $A=[0,1]$ and $B=[15 / 8,2]$ are two closed subsets of $\mathbb{R}$. Define $T: A \rightarrow B$ by $T x=-\frac{1}{8} x+2$. Define $\beta$ : $(0, \infty) \rightarrow[0,1)$ by $\beta(t)=\frac{1}{1+t}$ and $\psi:[0, \infty) \rightarrow[0, \infty)$ by $\psi(t)=\frac{1}{2} t$. Clearly, $d(A, B)=7 / 8$. Now we have

$$
\begin{aligned}
& A_{0}=\{x \in A: d(x, y)=d(A, B)=7 / 8 \text { for some } y \in B\}=\{1\}, \\
& B_{0}=\{y \in B: d(x, y)=d(A, B)=7 / 8 \text { for some } x \in A\}=\{15 / 8\} .
\end{aligned}
$$

Also, $T\left(A_{0}\right)=B_{0}$. Further, clearly, the pair $(A, B)$ has the $P$-property. Let $x, y \in A$. Note that, if $x=y$, then condition (6) holds. Hence, we assume that $x \neq y$. We shall show that (6) holds. Suppose, on the contrary, there exist $x_{0}, y_{0} \in A$ such that

$$
\psi\left(d\left(T x_{0}, T y_{0}\right)\right)>\beta\left(\psi\left(d\left(x_{0}, y_{0}\right)\right)\right) \psi\left(d\left(x_{0}, y_{0}\right)\right)
$$

and so

$$
\frac{1}{2} \times \frac{1}{8}\left|x_{0}-y_{0}\right|>\frac{\frac{1}{2}\left|x_{0}-y_{0}\right|}{1+\frac{1}{2}\left|x_{0}-y_{0}\right|}
$$

which yields that $14<\left|x_{0}-y_{0}\right|$, a contradiction. Therefore condition (6) holds for all $x, y \in A$. Hence, the conditions of Theorem 2.1 hold and $T$ has a unique best proximity point. Here, $x=1$ is the best proximity point of $T$.

\section{Competing interests}

The author declares that he has no competing interests.

\section{Acknowledgements}

The author expresses his gratitude to the anonymous referees for constructive and useful remarks, comments and suggestions.

Received: 12 March 2013 Accepted: 17 May 2013 Published: 24 July 2013

\section{References}

1. Banach, S: Sur les opérations dans les ensembles abstraits et leur application aux équations intégrales. Fundam. Math. 3, 133-181 (1922)

2. Geraghty, M: On contractive mappings. Proc. Am. Math. Soc. 40, 604-608 (1973)

3. Al-Thagafi, MA, Shahzad, N: Convergence and existence results for best proximity points. Nonlinear Anal. 70, 3665-3671 (2009)

4. Anuradha, J, Veeramani, P: Proximal pointwise contraction. Topol. Appl. 156, 2942-2948 (2009)

5. Basha, SS, Veeramani, P: Best proximity pair theorems for multifunctions with open fibres. J. Approx. Theory 103, 119-129 (2000)

6. Caballero, J, Harjani, J, Sadarangani, K: A best proximity point theorem for Geraghty-contractions. Fixed Point Theory Appl. 2012, 231 (2012)

7. Jleli, M, Samet, B: Best proximity points for $\alpha$ - $\psi$-proximal contractive type mappings and applications. Bull. Sci. Math. (in press). doi:10.1016/j.bulsci.2013.02.003

8. Eldred, AA, Veeramani, P: Existence and convergence of best proximity points. J. Math. Anal. Appl. 323, 1001-1006 (2006)

9. De la Sen, M: Fixed point and best proximity theorems under two classes of integral-type contractive conditions in uniform metric spaces. Fixed Point Theory Appl. 2010, Art. ID 510974 (2010)

10. Karapınar, E: Best proximity points of cyclic mappings. Appl. Math. Lett. 25(11), 1761-1766 (2012)

11. Karapınar, E, Erhan, IM: Best proximity point on different type contractions. Appl. Math. Inf. Sci. 3(3), 342-353 (2011)

12. Karapınar, E: Best proximity points of Kannan type cyclic weak $\phi$-contractions in ordered metric spaces. An. Univ. Ovidius Constanţa 20(3), 51-64 (2012)

13. Kirk, WA, Reich, S, Veeramani, P: Proximinal retracts and best proximity pair theorems. Numer. Funct. Anal. Optim. 24 851-862 (2003)

14. Markin, J, Shahzad, N: Best approximation theorems for nonexpansive and condensing mappings in hyperconvex spaces. Nonlinear Anal. 70, 2435-2441 (2009) 
15. Pragadeeswarar, $\mathrm{V}$, Marudai, M: Best proximity points: approximation and optimization in partially ordered metric spaces. Optim. Lett. (2012). doi:10.1007/s11590-012-0529-x

16. Mongkolkeha, C, Cho, YJ, Kumam, P: Best proximity points for generalized proximal C-contraction mappings in metric spaces with partial orders. J. Inequal. Appl. 2013, 94 (2013)

17. Raj, VS, Veeramani, P: Best proximity pair theorems for relatively nonexpansive mappings. Appl. Gen. Topol. 10, 21-28 (2009)

18. Raj, VS: A best proximity theorem for weakly contractive non-self mappings. Nonlinear Anal. 74, 4804-4808 (2011)

19. Raj, VS: Banach's contraction principle for non-self mappings. Preprint

20. Samet, B: Some results on best proximity points. J. Optim. Theory Appl. (2013). doi:10.1007/s10957-013-0269-9

21. Sintunavarat, W, Kumam, P: Coupled best proximity point theorem in metric spaces. Fixed Point Theory Appl. 2012, $93(2012)$

22. Shahzad, N, Basha, SS, Jeyaraj, R: Common best proximity points: global optimal solutions. J. Optim. Theory Appl. 148 69-78 (2011)

23. Srinivasan, PS: Best proximity pair theorems. Acta Sci. Math. 67, 421-429 (2001)

doi:10.1186/1687-1812-2013-200

Cite this article as: Karapınar: On best proximity point of $\psi$-Geraghty contractions. Fixed Point Theory and Applications $20132013: 200$

\section{Submit your manuscript to a SpringerOpen ${ }^{\circ}$ journal and benefit from:}

- Convenient online submission

- Rigorous peer review

- Immediate publication on acceptance

- Open access: articles freely available online

- High visibility within the field

- Retaining the copyright to your article 